\title{
Update of fasciolosis- transmitting snails from Tawarga, Libya
}

\author{
F. S. El-Serety ${ }^{1}$, A. H. Hadad ${ }^{1}$, D.Al-Bassel ${ }^{2}$ \\ ${ }^{1}$ Higher Institute for Medical Technology, Misurata, Libya. and ${ }^{2}$ Zoology Department, Faculty of \\ Science, Fayoum University, Egypt.
}

Out of 50 Biomphalaria alexandrina snails $25(50 \%)$ were found infected with Fasciola spp. This snail species is the suitable intermediate host of Schistosoma mansoni . It is worthy to mention that this is the first record of Fasciola in Libya which represent a new locality record.

Tawarga pond occupied an arid area at 38 $\mathrm{km}$ east Misurata city in Libya. This the endemic area of Leishmaniasis and Schistosomiasis in Libya. Biomphalaria alexandrina snail was translocated to the pond of Tawarga with fingerlings of Tilapia spp. fishes emerged into the pond before 20 years ago ( Libyain center for preservation of tropical and endemic diseases ,2005)

\section{Materials and methods}

Live snails were collected from Tawarga ponds in Musurata in Libya and identified as Biomphalaria alexandrina according to (Delucena, 1953 and Mandahl -Barth ,1962).

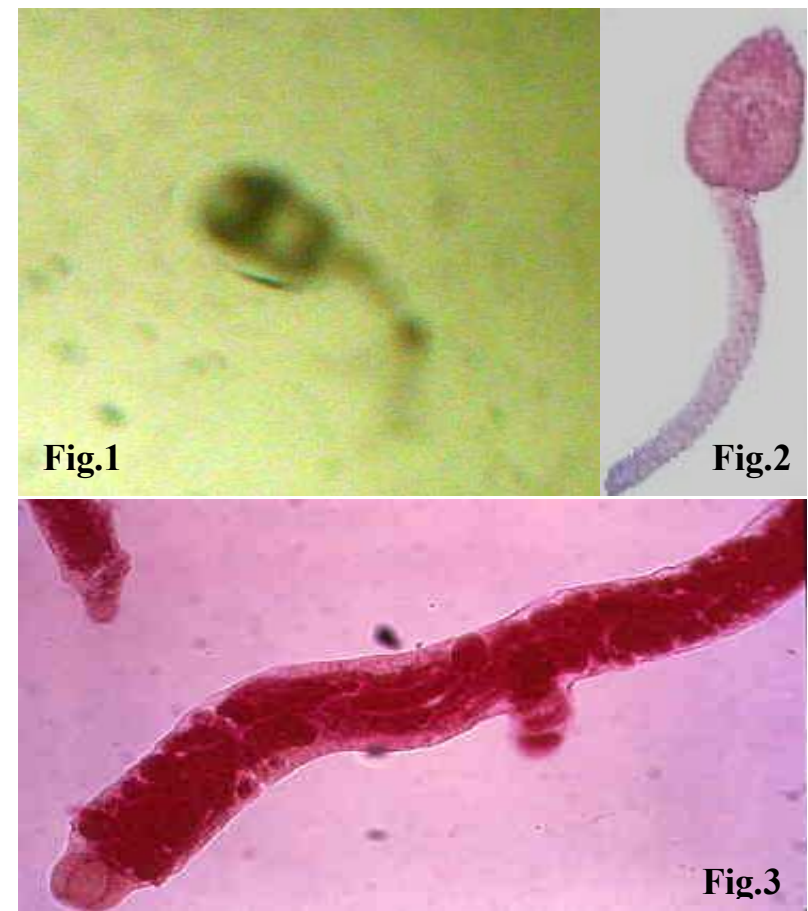

Each snail was crushed between two slides and examined by low power microscope for larval stages of trematode parasites. Specimens were fixed in $4 \%$ formalin. The specimens stained by acetic acid alum-carmine stain, dehydrated, cleared and mounted .Identification of cercariae according to (Faltynkova et al., 2008).

\section{Results and Discussion}

During the routine work for searching Schistosoma cercariae in their snail host Biomphalaria alexandrina. The authors found cercariae (Figs.1,2) and rediae (Fig. 3) of Fasciola spp. The present study revealed that ,out of 50 Biomphalaria alexandrina snails 25 (50\%) were found naturally infected with Fasciola spp. Parasites were detected and identified as cercariae and rediae of Fasciola spp. according to (Faltynkova et al., 2008). Previous studies revealed $100 \%$ experimental infection of snail Pseudosuccinea columella with miracidium of Fasciola spp. as new host record in France (Pointier et al., 2007) . So far, the presence of this snail in Europe as intermediate host of Fasciola (Pullan, 1969; Ponder, 1975; Ditrich , et al., 1992; Hechinger,2007). In Tunisia, Hammami et al., 2007 reported human infection of fasciola in three habitats. The prevalence of human infection was $6.6 \%$ while the presence of the parasite was detected $14.3 \%, 35 \%$ and 68.4 $\%$ in cattle , sheep and goats respectively .In Egypt, Dar et al., 2005 reported Biomphalaria alexandrina snail was naturally infected with Fasciola spp. They were not recorded the incidence of infection. The present work was found $50 \%$ naturally infected, as the first record in Libya and added the incidence $(50 \%)$ of 
infection. The prevalence of the infection of intermediate host Galba truncatula (G. truncatula) with Fasciola spp. were 19.2\% from Tunisia (Hammami et al., 2007; Czapski, 1965)

\section{References}

Libyain center for preservation of tropical and endemic diseases press (2005)

Czapski, Z. (1965): Studies on the biology of Galba occulta jack. 1959 a new intermediate host of Fasciola hepatica. Wiad Parazytol., 11:273-277.

Dar, Y. D.; Rondelaud, D. and Dreyfuss, G. (2005): Update of Fasciolosis- transmitting snails in Egypt (review and comment) J Egypt Soc. Parasitol., 35: 477-290.

Delucena, D.T. (1953): Tentative key for the identification of Brazilian species of mollusks of the Planorbidae family. Rev Bras Malariol Doencas Trop., 5:245-248.

Ditrich, O.; Nasincova, V.; Scholz, T. and Giboda, M. (1992): Larval stages of medically important flukes (Trematoda) from Vientiane province, Laos. Part 2 cercariae. Ann. Parasitol. Hum. Comp., 67:75-81.

Faltynkova, A.; Nasincova, V. and Kablaskova, L. (2008): Larval trematodes (Digenea) of planorbid snails
(Gastropoda: Pulmonata) in Central Europe : a survey of species and key to their identification. Syst Parasitol., 69: 155- 178.

Hammami, H.; Hamed, N. and Ayadi, A. (2007): Epidemiological studies on Fasciola hepatica in Gafsa Oases (south west of Tunisia). Parasitol., 14: 261-264.

Hechinger R. F. Annotated (2007): Key to the trematode species infecting Batillaria attramentaria as first intermediate host. Parasitol Int., 56:287-296.

Mandahl -Barth, G. (1962): Key to the identification of east and central African freshwater snails of medical and veterinary importance. Bull. WHO, 27:135-50

Pointier, J.P.; Coustau, C.; Rondelaud, D. and Theron, A. (2007): Pseudosuccinea columella (Gastropoda, Lymnaeidae), snail host of Fasciola hepatica: first record for France in the wild. Parasitol. Res., 101:1389- 1392.

Ponder, W. F. (1975): The occurrence of Lymnaea (pseudosuccinea) columella, an intermediate host of Fasciola hepatica in Australia. Aust. Vet. J., 51:494-495.

Pullan, N. B. (1969): The first report in New Zealand of Lymnaea Say (Mollusca: Gastropoda) an intermediate host of the liver fluke Fasciola hepatica .N Z Vet. J., 17: 255-6.

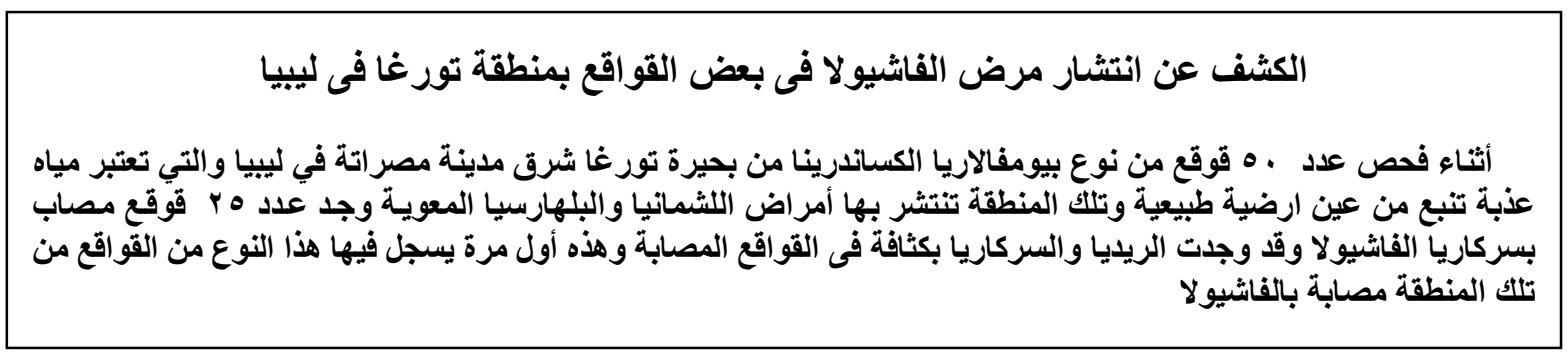

